LITERARY ANALYSIS AND EXPOSITION:

T'HE SECOND LANGURGE READER-WRITER.

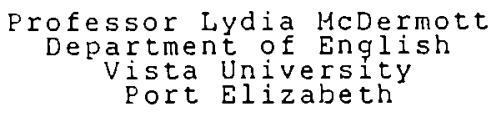

I am very aware that there are some whose presence at this conference makes my paper a 'sermon' to the converted. For this I apologise. ( I have, in fact, been warned by an already long-time practitioner of Africanisation, that, by presenting this paper, I will be re-inventing the wheel - my experience at 'English' conferences, however, tells me otherwise!)

I do, however, feel that the time has come for open

discussion on the necessary transformation of English studies in the 'new' South nfrica. There will have to be a transformation of English Studies, if it is not to become at best a useless quaint colonial relic, or at worst an instrument of disempowerment. Not only does the myth of a 'standard' language need to be demythologised, but so too the myths of a 'standard' critical practice, and a 'standard' point of view - in fact the whole myth surrounding the term 'standard'. All 'standards' are in fact rooted in the validation of our ideology - Western civilization. Whether we acknowledge it or not, we are in fact privileging and entrenching - and enforcingl - our particular historical, cultural and socio-political system at the expense of other systems.

As second language students are likely to be the new student population of English departments in the very near future, it is perhaps opportune to comment on some of the still 'negative' attitudes prevailing towards them in some guarters and to report briefly on the creativity in course design and on the changing attitudes to English 'competency' of which I have become aware. Unfortunately, most innovators are working in isolation, not only from other English departments, but even within their own departments. It would be to everyone's advantage, and more cost and time effective 
if there were a forum at which we could pool our ideas, our experience and our expertise. This conference and the English Academy and SAALA conferences to be held in cape Town at the beginning of July are a start.

This paper moves sequentially through five related areas of interest. Firstly, I shall give a brief justiflcation for the role I believe Linguistics could play in English studies in the future. Secondly, I shall present my perceptions of the status guo prevalling in English Studies and of the attitudes it apparently still has towards second language learners in its discipline, the Africanisation of syllabuses, and post-New Critical literary theory. Thirdly, I shall present what I believe the alternatives are for the reassessment of 'standard' language and the development of appropriate language skills in a 'new South Africa', either from within English studies, itself, or with the support of Linguistics. Eourthly, I shall give some practical examples in support of my plea to place critique before criticism by distinguishing between language errors which distort meandng and those which do not; a plea that in essence seeks to distinguish language deficit from language variability. Fifthly, I shall outline some of the 'South-Africanised' courses, of which I am aware, which are either already functioning or are to be instituted in the near future.

(Virtually all the examples and data I shall be using, except where so noted, are from personal experience. In the Eastern Cape there is a 'working group' of lecturers from the universities of Rhodes, Vista, Fort Hare, and UPE. The group is composed of interested staff from the Linguistics, ASP and English departments at Rhodes, and the English departments of the other institutions mentioned. Most of the language examples I use later in the paper are drawn from a pllot course on 'Language and writing skills' which I ran for six months in 1991, on behalf of the Departments of Business Economics and Law at the Port Elizabeth Vista campus.) 
The increase in second language students in English departments will have two major consequences: it will effect changes in teaching strategies, course design and critical techniques and will necessitate a complete re-think of the process of analytical exposition through the medium of 'standard' English. It is linguistically accepted that our reading, speaking and writing vocabularies decrease in the given order, and this accounts for the ability of most second language students to read prescribed texts with reasonable facility; given sufficient time in which to read at their own pace. The problem arises when they have to give an exposition of their reading of a text, particularly when that text arises out of a culture and history removed from their own. But, there is yet another problem: African students hear, and frequently speak, with 'tone language ears and tongues' and are faced with being lectured to by a great diversity of English 'accents'. And there 1 s more! Where they are lectured to in other disciplines by lecturers who are second language speakers themselves, they are exposed to yet other so-called sub-standard dialects. While there seems to be little one can do at present to resolve the 'accent. problem other than devise listening strategies (possibly using deep immersion listening techniques) ${ }^{1}$, there certainly are possible solutions for the written 'sub-standard English' problem. But this will require a complete re-assessment of the shibboleth of 'good English' by English lecturers. Then, a critical re-evaluation of the construct 'canon' and, concomitantly, a shift from the traditional teacher-as-expert critical practice tovards a lecturer-as-facilitator and student-as-experiencer critical practice will be necessary as empowering strategies. I believe that the whole process of course re-design entails the same kind of community consultation which is taking place in other sectors of the socio-political spectrum. We need to ask students what they perceive from their position their needs to be in their intellectual and day-to-day lives. We must aim to fulfil the 
needs of our potential student community, rather than, in our traditional way, prescribe what we believe its needs are from our Eurocentric positions. Already, I hear the cry but you will lower the standards!' As I will argue my case later, I ask you only to consider the question: 'Whose standards?'

It is in philosophical reconstruction that I believe linguistics as a discipline has a major role to play in supporting English Studies in its reconstruction to meet the needs of a changing south African world. I believe this, largely because modern linguistics as a discipline reveals itself to be far less prescriptive than English studies (or perhaps, the literary studies of all languages). On a practical level, I believe that it is linguists who are best suited to design and devise the language as process/writing skills courses all students of English at university need to attend - I am here deliberately including first Language students - because linguists have a theoretical training which enables them to analyse empirical language data in a way English teachers are not able to do. Furthermore, linguistics as a discipline has sub-disciplines, the existential validation of which is rooted in language as a social/cultural construct and language in use. I further believe it is possible for lingulstics to guide literary studies away from mere criticism of student work to critique of it, through making literature teachers conscious of the linguistic, and specifically the communicative, validity of many so-called non-standard English forms (the deficit) variability distinction). I also believe that a basic knowledge of Linguistics can be a means of entry into texts and to the analytical process, as well as the key to language structure 'consciousness raising'. It is through the latter that both lecturers and students will learn to evaluate language structures; lecturers in their assessment of student expositions and students in their creation of expositions.

The changing political climate in south Africa has led 
rapidly to the necessity for an urgent re-think of the teaching/lecturing strategies traditionally employed in south African universities. In fact, there are loud volces which would question the use of the term 'teach' in relation to our universities. Without entering into the debate on past university teaching practice in South Africa, I do want to look at the changes in teaching practice which I believe will be necessary for the successful education of a changing student population.

Up to now, most of the 'establishment' residential universities, no matter what their language preference, have been 'colonial' institutions which have privileged one of the two official languages as medium of instruction. (UPE, of course, has been the 'bilingual experiment' but its success or fallure is not what concerns me in this paper.) Typically, although seldom openly, the 'black'/ 'ethnic'/ 'homeland' universities have been seen as 'bush colleges' good only as stepping-stones for high-flying aspirant academics to enter the traditional ivory tower of academe. In fact, even in the last six months there have been questions about the role of the (newly categorised) black universities. Even more disturbing are the often snide implications about standards at the black universities. Yet, as I hope to show, it is from the experience of the 'black' universities that much can be learned about the kind of cross-cultural, second/third language teaching strategies needed for the new student community. These universities are at the workface of future university education - not just English university education.

One can only ask oneself how much of the 'apartheid university' criticism is directly attributable to the shrinking student numbers at some of the 'establishment' universities and their attempts to tap into, what must seem to them, to be an ocean of potential students. People's memorles, however, are unfortunately not that short, and much will have to be done by some institutions to gain credibility 
before they will be able to tap into this so-called new market, or, for that matter, into the overseas funding pool about which so many dream. Not even so-called liberal institutions will escape the 'what did you do in the war?' question - as the disturbances at UCT last year would seem to suggest.

A major criticism against the 'liberal' universities is that they create a Western-type elitist class which divorces its black students from the community-at-large's struggle. A further criticism has been that fees are so high, that the majority of potential applicants from the disadvantaged groups are excluded in any case. The accusation is also levelled that western white elitist ideology is covertly sustained and 'protected' by having entrance tests that privilege those who are already part of the 'Establishment'/ 'Eurocentric world'/First world'.2 Even the concept of 'Affirmative action' must be questioned if it merely means allowing the disadvantaged to enter the already privileged system from a lower point. All such Affirmative Action achieves is the entrenchment and overt legitimisation of the Eurocentric system which created the environment of disadvantage in the first place. Furthermore, it still assumes that there is some sort of universal utopian reality and truth system to which everyone must aspire land conspire!) if s/he wishes to 'truly' join the ranks of the civilized/cultured/educated. The time has indeed come for the Africanisation of English syllabuses. But, if such Africanisation is not to be mere window-dressing, the appropriateness and validity of the traditional Establishment insistence on a particular critical practice (frequently) and on a 'standard' language of exposition (nearly always), must be re-assessed.

It is in the insistence on readings of literary texts which are limited to the text's cultural and historical genesis, that I believe most of the difflculties of the academics of a 
new 'university' South Africa will lie. By demanding that their second language students study and must analyse traditional canonical texts from Eurocentric establishment positions and in 'standard' English, university teachers are disempowering those they profess to wish to educatel This disempowerment functions on at least three levels: the choice of canonical texts, the privileging of particular critical practices, and the evaluation of written critical exposition.

In many English Studies departments, the Africanisation of syllabuses is seen as a lowering of standards because the 'canon'/the 'great tradition' has to be reduced to include in the syllabus works of 'inferior quality' $/$ momentary interest'; works which have been deemed by, often invisible, culturally-biased literary doyens as structurally and linguistically inadequate and non-literary; not universal! Thus some of the less caustic Establishment criticisms against syllabus Africanisation. Yet few of the antiAfricanisation voices stop to consider that what we claim to be developing in students is the critical faculty, which even they would surely not claim depends on the 'Great Tradition' of British English texts!

Add to this the apparently still common belief that there is really only one kind of valid literary criticism which must be handed on to students by lecturers to be used by students as a 'truth' and you get a kind of literary critical bigotry, or to use the 'in' phrase, 'ideology', which oppresses a student's choice of 'Marxist/Feminist/structuralist/Poststructuralist readings and privileges what amounts to 'New criticism'. Such criticism, which is descriptive rather than analytical, assumes the mastery of the text over the reader rather than a process of interaction - Inter-textuality between the text and the reader based on the text's historical, cultural, socio-political positions and those of the reader.

One practitioner of New criticism, for example, rejects post- 
colonial readings of eighteenth century texts as invalid, simply on the grounds that such a theory had no meaning in that historical period. Such critics see most modern reading theories as imposing politics on unique literary texts. (one can only assume that such readers see texts as objects, each with 1ts own meaning, rather than as a process of meanings.)

Feminist readings particularly have come in for a hard knock, the criticisms are, more often than not, levelled at the person of the critic, rather than at the analysis itselfl Many 'traditional' readers even deny the appropriateness and validity of feminist readings of texts which make women invisible/supports/oddities, even though in such texts women may be: ignored completely; reduced to nameless, ineffectual, inferior shadows on the stage of the active all-powerful, heroic/villainous male characters; caricatured; portrayed as harlots at heart!

New Critical readers frequently justify their criticisms by claiming that in all texts there are author-directed focuses/ main 1ssues, the analysis of which, must take precedence over all focuses. These readers do not concede, perhaps because they do not perceive, that such a privileging of authorial focus as 'primary' is the direct result of a particular historical, socio-political process and that a prescribed approach to a text must lead to the oppression of the critical freedom of a reader who has been conditioned by a different historical experience. The existence of so-called 'main issues' 1 s also dubious, precisely Eecause texts are In history, and as such are read in the light of changing cultural and socio-political experiences. 'Traditional' critics seem not to associate the fact that there are 'Iiterary fashions' which privilege kipling in one generation and reject him in the next, with the same historical sociopolitical influences about which we have been speaking.

Yet one might say that 'It's all in an outlook'. If this is so, then those who shy away from what they see as the 
politicisation of the 'sacred cow', called 'literature', need only to re-adjust their literary focus from past historical positions relating to a literary canon, the authority of the text' and 'permissible' critical techniques to a present historical position of reading/interpretation as a process entailing an historically-rooted symbiotic relationship which holds among author, text and reader. The acceptance of this position allows for literary analyses in a paradoxical way free from history, because it acknowledges all readings as historically (and, thus socio-politically) informed readings which will be extended/altered in the process of history. only when it is accepted that literature and literary criticism, and language usage are part of the process of variant historical experience and thus subject to change, will the infallibility of Establishment Eurocentric English studies and English language be denied. Only then, will inhibiting beliefs in 'canon', 'the meaning of the text'. 'intentional fallacy', 'authority of the text' - the superiority of English Establishment Eurocentricism - be demystified. Only then, will an authentic African (decolonised) 'Ianguage culture of criticism' be able to find legitimacy alongside our authentic critical positions whatever they may be. (I am not unaware that I am pleading from a particular ideological position, but I can only escape from a one position to another, never being ideologically bound I)

Only too often, instead of students actually being taught to think critically and independently as we so often claim, they are taught to conform to an already privileged critical system (if they wish to pass that is!). They are seldom taught to ask questions of a text and to ask themselves what questions the text itself is asking, or, cruclally, to ask what ideological positions a text is promoting - or concealing. They are seldom given the chance to examine a text in terms of the 1 ssues which are relevant to them and their experience of the world. Some students have even 
reported that their readings of south African texts from an African perspective have been condemned as politics not literary criticism. Such reports have been unsolicited and represent three of the 'establishment' universities. All the students concerned have been black students doing post graduate degrees. I believe it is at the peril of our academic and vocational credibilty that we ignore either the female voice or the voice of the still educationally and culturally oppressed masses. I believe that a lecturer's position vis a vis students should be that of a facilitator of critical learning not a dictator of critical practice. I believe that imposing a 'standard' English is both equally perilous and unjust.

English students, because they are English students, are usually expected to present their analytical expositions in a 'correct' linguistic form. Judging by many evaluators' marking comments, the lecturer-percelved correctness of the language and spelling of the exposition takes precedence over the critical argument. Disturbingly, little concern seems to be shown by the average English lecturer for the student whose critical ability might be excellent, but who lacks the linguistic facility necessary for analytical expositions which will meet the 'standard'. (I have even heard it said of such students that "their muddled language is an expression of their muddled minds', without cognisance being taken of the fact that it is a lack of the demanded so-called Standard English language skills which is the student's problem, not a lack of intellect.) Too few English lecturers are wllling to distinguish between those language errors which disrupt the communication process and those which do not. The argument, that all language errors disrupt the communication process, is disproved by the everyday acceptance by most of us of foreign language speakers' errors; if those speakers are academically recognised! We need to give our second language students the benefit of the same doubt - in fact not even Queen Victoria would have 
passed the 'Standard English' criteria demanded by some of our English lecturer colleagues! Her spelling and syntactic structures were far too inconsistent and idiosyncratic! And, who would dare tell the Americans that they speak and write Americanese, not English? For some reason, the dialects of the 'white' colonies are academically acceptable, but the South African African English dialect is not, and is in fact frequently seen by language pedants, as a sign of English illiteracy!

The 'establishment' universities have a particular problem, at least for the forseeable future, precisely because they will be dealing with a student population made up of a small educationally privileged group and a large educationally under-privileged group. If this is true of 'establishment' universities, at large, the difficulties facing 'traditional' English departments, given their nature and philosophy, are even more complex. Yet, almost frighteningly, their role as English departments is more important now than ever, particularly if, once the language politicians in the country reach consensus, English becomes a major national language (thereby, of course, privileging it) to be used in official communication along with other regional languages. I believe that English Departments will have to re-assess their function and their 'production' in the light of the language and educational needs of the country.

If it is the English departments who are going to take up the second language student challenge, then I believe that we wlll either have to return to the once common practice of having both a practical English and an English literature course, or integrate language components into our courses. I do not, however, envisage these as attempting to impose a 'Standard. English. Their aim should be to teach sufficient language to facilitate effective communication in English (and to develop effective reading strategies). There will have to be a grammar component precisely because there are 
errors which distort meaning, but such a component should lead to a personal ability to create and self-evaluate communicative effectiveness. A primary facet of such a course, one all students seem to need, is a writing skills course which entails inter alia question evaluation, research methodology, brainstorming, material organisation, logical presentation, referencing.

UPE, UNISA and the so-called Afrikaans universities have run Practical/special/Professional English courses for years.

(That some 'establishment' universities are already trying to grapple with the changing face of English studies is patent from the course re-design of departments like Rhodes, for example, but more about that later.) one would assume that the primary reason that the Afrikaans and bilingual universities (I include UNISA here) have 'practical' courses is because so many of their students who are registered for English are not mother-tongue English speakers, yet under the current dispensation need English as a compulsory ancillary before they can gain their professional accreditation/ certification. Teachers and lawyers certalnly fall into this category and would also benefit from the type of course outlined above.

A further need expressed at Vista, mainly by the professors of Business Economics and the Faculty of Law, is for a language component built into their subject courses. We would envisage such a component as comprising a basic language/ writing skills segment and a subject-speciflc segment. Funding being what it is, the practical implications are, of course, enormous. Who would teach this component - who has the skills? Few literature lecturers have such skills (notwithstanding the fact that in many departments the number of second language students is already high), let alone the subject-specific knowledge and metalanguage necessary to teach a subject-specific language segment. On the other hand, few law or business subject-lecturers have the 
necessary language teaching theory and skills.

Rlthough 1t has been suggested that no-one learns a language from learning that language's formal grammar (the 'transference' debate), I would argue that linguistic/ language awareness can and frequently does function as a language-rule consciousness-raising process; a formallsation of what is subconsclous. Furthermore, writing being a 'secondary' language skill, even mother tongue speakers, given the current privileging by 'language watch-dogs' of standard languages, have to learn to write a given language 'correctly'. I do not deny that grammar alone cannot teach a child a language, I deny only the claim that 'grammar' plays no role, at least in written language effectiveness sk1lis acquisition. Yet most English departments have given up their formal language role, so language-needy English students seldom find help in English departments.

Eurthermore, even if such students were to register for an available Gerieral Linguistics course, they would still not be given English-specific training. Most General Linguistic departments, by definition, are concerned primarliy with language description and theorlsing, and seldom with the study of one particular language.

English seems to me to be the only modern language taught at university, which has given up its language-linguistic component entirely. All other modern language departments appear to have retained language and linguistic segments alongside the literary segments. That this is partly due to the demands of school syllabuses is obvious. English school syllabus designers overseas discarded 'grammar' in the early seventies and South Africa blindly followed some years later, replacing grammar with 'creative writing'. While I would not wish to give the impression that I support rote learning or prescriptiveness, which would in any case contradict the básic premise of my paper, I do believe that language and writing are skills-based and have to be taught as such, not 
only to second language learners, but to mother tongue learners as well! It is here that I believe Linguistic departments could play a major practical role.

There are at least two alternatives open to Linguistics departments willing to work with English departments. They could either teach a language awareness and skills segment which is incorporated into an English course, as Rhodes used to do (but only on first year level), or they can endeavour to have Linguistics 1 made a compulsory ancillary for all students registered for English. In both cases, the Linguistics departments would have to re-design their courses to include language and writing skills, but exclude linguistic theory proper - a sort of practical linguistics course. The advantages of Linguistics departments providing English language and skills courses include pragmatic things like 'guaranteed' student numbers and thus stafing points, but also, for me even more crucially, they already have the theoretically-based expertise needed to design courses and devise strategies at a time when less theoretically based creativity could lead to hit-and-miss affairs; surely the last thing we can afford given the state of education in this country and the demands already being made on English

departments. Furthermore, the language specialists $11 k e l y$ to employed by English departments are almost certainly going to be linguistically trained. It, thus, hardly seems logical or makes financial sense, to employ language specialists only as support persons for the literature to be taught. In any event, such persons seem to become marglnalised as 'practical/language' lecturers who are seldom able to advance up the academic ladder; the literature lecturers being considered the 'legltimate' English lecturers. This is only too frequently so, notwithstanding the fact that often the 'practical' classes are far larger than the 'proper' classes and as such, carry the rest of the department on their student numbers. Even more unfairly, practical teachers are usually expected to carry the practical course single- 
handedly; marking, course designing, small-group teaching and all.

In order to substantiate my plea for critique not criticism, I would like to turn briefly to more practical language concerns by highlighting a few examples of those errors which affect meaning and those which do not. I plead also that an 'error' repeated is still only one error and should be treated as such. As my students are mainly xhosa and Afrikaans mother-tongue speakers, my data is drawn exclusively from these second language user groups.

$A$ pet 'can-s/he-write-English?' criterion is subject-verb concord. Yet, even the best of mother-tongue speaker-writers commits this sin occasionally. Concord errors like split infinitives might be 'bad' English, but they can hardly be said to obscure meaning. What about the transference into writing of the spoken elision of contracted forms like could've/should've/would've, as could of/should of/would of? These might be 'wrong', but they hardly affect the communication process. It is highly likely that they will become an example of phonological change and so in their turn chey will become a synchronic norm. Other structures which apparently do not.result in meaning loss when they are used 'ungrammatically' include: most sentence order, appositional insertions, sequence of tense, and the continuous tense. Misspellings are only infrequently problematic.

Structures which do affect meaning, and which I would then quite willingly call 'ungrammatical', include: pronoun use, some deictic parts of speech (including directional verbs), cause and effect sentence order, synonyms, and idiomatic expressions. While pronoun-noun agreement and anaphora, and cause and effect can be taught formally, it seems that the only way in which to make 'instinctive' the correct use of preposttions and ldiomatic expressions and the correct choice of an appropriate synonym, is by deep immersion through hearing, reading and writing. Some English departments have 
already begun to look to such second language learner needs.

Rhodes has this year. (1992) re-instituted a language-focused course for those not wishing to major in English. In English A, which runs parallel to the English 1 course, students spend half the year developing and practising writing skills and the rest applying these skills to a study of prose and drama. They study no poetry and the course is noncontinuing. The English 1 students are also required to do a writing component, but only for one term. The skills learnt are practised in conjunction with prose study. Poetry and drama are studied in the second half of the year. African texts have also been included in the courses.

UWC, under the auspices of the 'Bels' project, 3 has already produced a most useful writing skills text and the English Department has also re-designed 1ts English 1 course. The first year course has both a language and literature component. Running concurrently with the English programme is a 'peer tutoring programme'. It is in this programme that the skills learnt in the language component of English 1 proper are practised in expositions of the literary texts studied in component two of the overall course. (The literature component has both a South African module and a literary survey module.)

The UDW English department seems to have the most tested and developed course. The basic departmental premise is that no language/dialect is superior to any other. The underlying theoretical position is materialist. In fact, the department teaches literary theory from the first year in the belief that in considering various theoretical alternatives, one is developing the students' life and intellectual skills. UDW has two English courses: English T ('Terminating') and English as a three-year major. Themes such as 'Language and power', 'Language and society', 'Modernism and postmodernism' anchor the courses within the notion of relevance. The department puts out its own workbook which covers a range 
of texts and a variety of modes of discourse covering the topics of Education, Gender, Environment and Politics.s There is no language segment at all, which seems to me to be short-sighted, even if all 'dialects' are given equal status.

Vista is currently re-designing all its undergraduate courses and its Honours course. These will be progressively phased in only from 1994, but adjustments are continually being made to the current. courses where this is possible without inclting the ire of the booksellers and/or needing senate approval. The first year course will be presented as modules in which language and writing skills are integrated with poetry. The students study prose and drama in the second half of the year. Both the second and third year courses use a cross-generic locus approach, including loci such as gender, post colonialism, 'writing the self'. 'While the second year makes pragmatic use of a reader-response approach from a Marxist position, the third year formalises the second year work by both critically examining Marxist and Feminist literary theory and the post-colonial reading approach, and by using them explicitly as tools for the literary analysis of a wide range of texts.

Other English departments are also in the process of redesigning their courses, but I know too little about them at present to comment. Perhaps the time has come to have a conference on the nature of English departments in the 'new' South Africa. Such a conference would at least provide a forum at which interested parties could share their problems, experiences and ideas, and much 're-invention of the wheel' would be prevented.

\section{END NOTES}

1 UDW uses such techniques; see text, page 17.

2 For a comprehensive discussion, compare christie 1985, Chapters $4-10$ and although centred on the American second language situation, Edelsky 1991 . 
http://spilplus.journals.ac.za/

4 Justus et al 1992.

5 Eorthcoming by professor A. Brimer in a forthcoming Journal of Literary studies.

\section{BIBLIOGRAPHY}

Christie, P.

Edelsky, C.

Justus, J-A. ,

Tuckér $P$. ánd

T. Volbrecht.
1985. The right to learn: the strugale fol

education in South AErica.

Braamfontein: Ravan Eress, 1991.

1991. With justice and literacy for all. London: The Falmer Fress.

1992. The basic English language skills book for students at tertiary level Cape Town: David Philip. 